\title{
SPIRITUALITÄT, DICHTUNG UND KOMPOSITION. DIE VARIABLEN ENTWICKLUNGSEBENEN DES ITALIENISCHEN ORATORIUMS
}

Der geschichtliche Verlauf des italienischen Oratoriums zeigt bezüglich Entwicklung, Funktionalität und Rezeption so viele Oszillationen, dass es angebracht erscheint, von einer außerordentlich komplexen Gattung zu sprechen. Etymologisch betrachtet erweist sich schon die Bezeichnung, Oratorium' als eine Metonymie; die hybride Stellung zwischen geistlichem und weltlichem Bereich sowie die formale Nähe zur Oper tun dann ein übliches. Auch hat die nachträgliche, überdeckende Konsolidierung des händelschen und haydnschen Oratorientyps bewirkt, dass die unstreitbare Dominanz des italienischen Modells im 18. Jahrhundert relativ wenig Beachtung erfährt. ${ }^{1}$

Zwischen dem Ursprung in den gegenreformatorisch inspirierten geistlichen Übungen des Filippo Neri (1515-1595) und dem morphologisch der Oper angepassten Endprodukt ab der zweiten Hälfte des 17. Jahrhunderts erstreckt sich eine eigentümliche Entwicklungsphase; ziemlich anders als bei der weltlichen Schwestergattung, deren Verlauf vom humanistischen Experiment, über die höfische Unterhaltung zum impresarialen Spektakel für ein bezahlendes Publikum, sich ungleich linearer gestaltet. Doch ist unleugbar, dass die formalen Unterschiede zwischen Oratorium und Oper italienischen Zuschnitts nur geringfügig sind, wobei im ersten drei besonders hervorstechen: der geistliche Stoff, die Zweiteiligkeit und die nicht szenische Aufführung. Man sollte bedenken, dass Librettisten, Komponisten und ausführende Sänger und Musiker immer dieselben waren; auch aus dieser Tatsache wird verständlich, dass das Oratorium rezeptionsästhetisch häufig als Ersatz für die Oper herhielt, welche ihrerseits zur Fastenzeit nicht aufgeführt werden konnte. Bei beiden spielten lokale Traditionen

1 Zum italienischen Oratorium im besonderen siehe folgende Monographien: PASQUETTI, Guido. L'oratorio musicale in Italia. Firenze: Successori Le Monnier, 1906, ALALEONA, Domenico. Storia dell'Oratorio Musicale in Italia. Torino: Bocca, 1908, HERCZOG, Johann. Il perfetto melodramma spirituale. L'oratorio italiano nel suo periodo classico. Roma: Istituto di Bibliografia Musicale, 2013. 
ebenso eine wichtige Rolle, doch das Spektrum des Oratoriums, in seiner Polyvalenz zwischen profunder Spiritualität, frommer Unterhaltung und politischer Botschaft, war viel weiter gefächert. Es ist offensichtlich, dass die entsprechende Komplexität religiösen und ideologischen Aspekten zugeschrieben werden muss, die eng mit der kontrollierenden und hinterfragenden Rolle der Amtskirche zusammenhingen.

Bei all seiner Vielschichtigkeit kann man für das italienische Oratorium immerhin drei konstituierende Faktoren herausschälen, die sein Selbstverständnis grundlegend bestimmen. Es handelt sich um seinen geistlichen Gehalt, seine literarische Umsetzung, schließlich um sein musikalisches Gewand. Besagte drei Faktoren sind andererseits recht variabel gewichtet, vor allem angesichts ihrer historischen Entwicklung. Auch hier tun sich diverse Unterschiede zur Oper auf, man kann jedenfalls prinzipiell festhalten, dass wenn die drei eben genannten, prägenden Bestandteile untereinander auf gleich hohem Niveau ein Gleichgewicht erreichen, es möglich wird, über einen klassischen Zustand zu reden. ${ }^{2}$ Solcher Zustand ist jedoch als schwebend anzusehen, weil er sich auf drei, stets in Bewegung begriffenen, unterschiedlichen Entwicklungsebenen realisiert, deren historische Abläufe eine besondere Aufmerksamkeit verdienen. Für die zeitliche Umgrenzung ist vorauszusetzen, dass die als ,klassisch' definierbare Periode des italienischen Oratoriums für den größten Teil des 18. Jahrhunderts fassbar ist; für die Betrachtung der entsprechenden Entwicklungsmechanismen ist jedoch die propädeutische Berücksichtigung vorhergehender Konfigurationen durchaus angebracht.

Es ist nützlich, sich hier daran zu erinnern, dass die spezifischen Entwicklungsstränge in der Kulturgeschichte in ihrer Abfolge einer temporären RegelmäBigkeit unterworfen sind, wie es der Blick auf jede traditionell umrissene Kulturepoche bestätigen kann. Jede sich neu formierende Kulturepoche wird anfangs durch einen philosophischen Unterbau vorgezeichnet, der dann von der Literatur dargestellt, erörtert und weitergetragen wird. An zweiter Stelle folgen, in all ihrer verzweigten Vielfalt, die bildenden Künste, handele es sich um Malerei, Skulptur, oder Architektur. Die Musik ist jene Kunst, die als letzte epochentypische Züge annimmt, und dies liegt vor allem an ihrer - von vielen Philosophen bewunderten - abstrakten Natur, die der Konkretisierung mittels Wort oder Bildhaftigkeit entbehrt. ${ }^{3}$ Für das italienische Oratorium heißt das, dass sein Entstehungsgrund, sein

2 Der hier verwendete Klassik-Begriff geht von der reifen Ausgewogenheit der angewendeten Mittel aus und nicht von einer epochalen - auch nicht sich der Antike anlehnenden - Definition. Zur Problematik der Klassik siehe OSTHOFF, Wolfgang. Einführung. In OSTHOFF, Wolfgang - WIESEND, Reinhard, ed. Colloquium Klassizität, Klassizismus, Klassik in der Musik um 1920-1950. Tutzing: Hans Schneider, 1988, S. 7-12.

3 Durch die hier dargelegte chronologische Inkongruenz zwischen den verschiedenen Kunstformen erklärt sich übrigens auch, weshalb Madrigalkomponisten im 16. Jahrhundert so oft auf Texte von Petrarca zurückgriffen: die Poesie des Renaissancedichters aus dem 13. Jahrhundert verband sich auf ideale Weise mit der erst später zur vollen Reife gelangten, entsprechenden Idiomatik der Musik. 
kausales Selbstverständnis, seine poetische Entfaltung und seine musikalische Vertonung einer zeitlich versetzten Evolution unterliegen. Und es liegt ein gewisser Reiz in der Feststellung, dass bei der Erschaffung eines jeden vokalen Werkes die zuerst erdachte Grundidee anschließend in Dichtung gegossen wird, um dann vertont zu werden. Beim italienischen Oratorium gesellt sich zum beschriebenen periodischen Aspekt allerdings ein reaktionärer Faktor, der der Gattung in ihrem Werdegang stets und unvermeidlich seinen Stempel aufdrückte: die prüfend besorgte Aufmerksamkeit der katholischen Kirche.

Als heikelste konstituierende Ingredienz des Oratoriums bezüglich seiner allgemeinen Entwicklungsfähigkeit muss man zweifellos ihren geistlichen Gehalt bezeichnen - handelt es sich doch auch um genau jenen Bestandteil, für den sich in der gleichzeitigen Oper keine Entsprechung findet. Wohl werden selbst im melodramma metastasianischer Prägung ethisch-moralische Inhalte behandelt, die gewöhnlich mit der Verherrlichung des Gottesgnadentums absolutistischen $\mathrm{Zu}$ schnitts einhergehen; bekanntlich sind diese aber, im Zuge des generellen geistesgeschichtlichen Prozesses in Europa zwischen dem 17. und dem 18. Jahrhundert, einer spezifischen Entwicklung vom Fideismus zum Rationalismus unterworfen. Im Oratorium aber bleibt das katholische Dogma als Konstante immer als solches bestehen, und seine Konzepte sollten in vielen intellektuellen Kreisen, noch hin bis zur französischen Revolution, immerhin eine gewisse Gültigkeit behalten. Dieser Umstand musste allerdings für einen zwar zutiefst gläubigen, aber doch schon auch rational denkenden Dichter, wie Pietro Metastasio, bei der Abfassung von Oratorienlibretti Schwierigkeiten bereiten. Die katholischen Glaubensinhalte waren unantastbar, selbst wenn ihr Niederschlag in der dramaturgischen Anlage der Handlung als unlogisch, teilweise auch als ungerecht, auf jeden Fall aber als störend empfunden werden konnte. Und diese Tatsache sollte dann letztlich zum vielleicht entscheidenden Grund für den endgültigen Verfall der Gattung gegen Ende des 18. Jahrhunderts werden.

Dennoch, geringfügige Wandlungen im Entwicklungsprozess können sich selbst in der inhaltlichen Ausrichtung, oder besser Akzentuierung, des geistlichen Gehalts beobachten. Als bezeichnendes Beispiel könnte man auf Verlagerungen bei der Stoffwahl hinweisen. Wenn im 17. Jahrhundert, hinsichtlich der Sujets, zwischen biblischen Episoden und Heiligenviten noch eine große Ausgewogenheit herrscht, so erscheinen im 18. Jahrhundert Libretti, die das Leben eines Heiligen verarbeiten, als schon ausgesprochen antiquiert. Die merkliche Abnahme in der Berücksichtigung von hagiographischen Inhalten müsste aber unbedingt als Ausdruck einer sich sogar auch in der Theologie subtil ausbreitenden rationalen Sichtweise bewertet werden. Ferner ist es notwendig, gerade in diesem Zusammenhang die große Bedeutung von lokalen Verhältnissen hervorzuheben. Der Einfluss der römischen Kirche in Italien, oder allgemein in ganz Europa, war nicht überall gleich, selbst wenn man nur katholisch ausgerichtete Zentren oder Gebiete in Rechnung zieht. Es gilt zu bedenken, dass dieser in Rom, Mittelpunkt der päpstlichen Macht, aber auch in Wien, Sitz der deutsch-römischen Kaiser, 
bestimmend war, während er in Neapel und in Venedig, aus ganz verschiedenen Gründen, weniger Bedeutung genoss. Aber es gab auch Sonderfälle, wie das katholische, aber gallikanisch durchwachsene Frankreich, das auf Eigenständigkeit pochte; oder das urprotestantische Sachsen, dessen Hof in Dresden jedoch katholisch war und dies in ideologischer und kultureller Beziehung auch unterstrich. All dies beeinflusste nicht nur die jeweilige Präsenz und Pflege des italienischen Oratoriums, sondern auch ihre stets wechselnde geistliche Durchdringung und erfordert mithin eine gesonderte Betrachtung.

Es bedarf keiner spezifischen Erklärung, dass in Rom, Hauptstadt des Kirchenstaates, der Katholizismus praktisch alle Bereiche des alltäglichen Lebens durchdrang. ${ }^{4}$ Ebenso gilt es zu erwägen, dass das Oratorium von den Nachfolgern des Heiligen Filippo Neri authentisch gepflegt wurde. Der Oratorianerorden hatte seinen Hauptsitz in Santa Maria in Vallicella - auch als Chiesa Nuova bekannt wo mustergültige Aufführungen stattfanden, genauso wie in der zweitwichtigsten Kirche der Philippiner, der San Girolamo della Carità. So schien der Werdegang der Gattung in seinem originären Habitat auf nahezu ideale Weise gewährleistet. Zweck der Praxis blieb dabei stets die geistlich-moralische Erbauung, zumeist für bürgerliche Bevölkerungsschichten. Oratorien wurden in der Ewigen Stadt allerdings auch in anderen Ambienten und Funktionen realisiert: so in Kollegien und sonstigen Bildungsanstalten, die gewöhnlich von religiösen Orden betrieben wurden, darunter den Jesuiten, den Piaristen und den Somaskern; hier stand das didaktische Prinzip im Vordergrund. Was die wichtige Rolle der Gesellschaft Jesu betrifft, so muss man herausstreichen, dass schon Ignatius von Loyola und Filippo Neri als Streitgefährten ähnliche pädagogische Methoden zur Erneuerung und Wiederbelebung des Katholizismus anwendeten, und ferner, dass es in den ersten Jahrzehnten des 17. Jahrhunderts mancherlei Verflechtungen zwischen den noch nicht voll ausgereiften Formen des Jesuitendramas und des Oratoriums gab. ${ }^{5}$

Im Gegensatz zu den Oratorianern, die nach der Vorgabe ihres Ordensgründers sich vornehmlich um das einfache Volk kümmerten, wandte sich das Interesse der Jesuiten schon früh der Elite der Gesellschaft zu. Aus diesem Grunde hatte in ihrer Methodik die lateinische Sprache eine herausragende Bedeutung. Folglich waren die in der an das Collegio Germanico-Ungarico angeschlossene Basilica di Sant'Apollinare abgesungenen Oratorien von Giacomo Carissimi fast ausnahmslos lateinisch und konnten sogar selbst von der Liturgie einverleibt werden. ${ }^{6}$ Lateinische Oratorien wurden ebenso von der in der Kirche San Marcello ansässigen Erzbruderschaft Santissimo Crocifisso in Auftrag gegeben, und auch diese hatten einen elitär-intellektuellen Anstrich, mit Affinität zu liturgischen Formen. Paraliturgisch angelegt waren aber auch die Weihnachtsoratorien, die alljährlich zur Heiligen Nacht im Apostolischen Palast erklangen: Ihr weihnachtliches, ge-

\footnotetext{
4 GIUNTELLA, Vittorio E. Roma nel Settecento. Bologna: Cappelli, 1971, S. XI-XV.

5 Siehe die Rappresentatione di Anima et di Corpo (1600) von Emilio de' Cavalieri, den Eumelio (1606) von Agostino Agazzari und auch den Sant'Alessio (1732) von Stefano Landi. 
wöhnlich allegorisches Sujet schloss sich thematisch der vorhergehenden ersten Vesper an und war so eher geistliche Übung als fromme Vergnügung; man konnte auch das nachfolgende Abendmahl als eine Art Agape verstehen, von der man organisch zur Mitternachtsmesse überging und damit ein am späten Nachmittag begonnenes Ritual zu Ende brachte. ${ }^{7}$

Von stark geistlichem Inhalt waren sogar die in Adelspalästen aufgeführten Oratorien, auch wenn ihre Entstehung oft mehr repräsentativen Überlegungen unterlag. Abgesehen vom Drang, die eigene - vor allem finanzielle - Potentialität zur Schau zu stellen, waren viele der aristokratischen Mäzenen mächtige Kirchenfürsten und von daher der geistlichen Perspektive verpflichtet. Doch wenn sich dieser Aspekt mit gesellschaftlichen und sogar auch politischen Zeichensetzungen anreichern konnte, war es umso besser. So entstanden in Rom, Schauplatz der europäischen Diplomatie zwischen dem Spanischen Erbfolgekrieg (1701-14) und der französischen Revolution, eine Reihe von ,politischen' Oratorien, und es oblag immer dem Geschick jeweiliger Autoren, die erwünschte Botschaft taktvoll zum Ausdruck zu bringen. ${ }^{8}$

Man sieht, die Spiritualität des Oratoriums blieb in Rom weitgehend bewahrt, obwohl ihre Funktionalität einer gewissen Auffächerung unterworfen war. Wenn es denn überhaupt zu Verweltlichungstendenzen kam, so geschah es auf ähnliche Weise wie in der gleichzeitigen reinen Kirchenmusik. Hier bietet es sich an, einen Blick auch auf die häufig zitierte Enzyklika Annus qui zu werfen, den Benedikt XIV. 1749 im Vorfeld des bevorstehenden Heiligen Jahres 1750 erließ. ${ }^{9}$ Man wird schnell feststellen, dass die betreffenden päpstlichen Vorgaben weder sonderlich genau definiert waren, noch die bewährte Morphologie des Oratoriums an ihrer Geburtsstätte erschüttern konnten - und überhaupt nur wenig Beachtung fanden. ${ }^{10}$

Wenn im kulturell schon seit dem 17. Jahrhundert stark italienisierten Wien auch das italienische Oratorium eine zentrale Heimstätte fand, so lag das nicht nur an den dynastischen Verbindungen zwischen dem Hause Habsburg und den Fürstenhöfen auf der apenninischen Halbinsel. Vielmehr muss man bedenken,

7

Ibid., S. 29.

FRANCHI, Saverio. Il principe Livio Odescalchi e l'oratorio 'politico'. In BESUTTI, Paola, ed. L'oratorio musicale italiano e i suoi contesti (secc. XVII-XVIII). Atti del Convegno Internazionale Perugia, Sagra Musicale Umbra, 18-20 settembre 1997. Firenze: Leo S. Olschki, 2002, S. 141-258. Antonio Caldara schrieb verschiedene politische Oratorien, so zum Beispiel das Oratorio di Santo Stefano primo re dell'Ungheria (1712). Durch Symbole und Andeutungen sollte das Werk eine Versöhnung zwischen Papst Clemens XI. und Kaiser Karl VI. in die Wege leiten.

BELLOCCI, Ugo, ed. Tutte le encicliche e i principali documenti pontifici emanati dal 1740. 250 anni di storia visti dalla Santa Sede. Roma: Libreria Editrice Vaticana, vol. I, Benedetto XIV (1740-1758), 1993.

Dies gilt, bezeichnenderweise gerade für Rom und Italien, während die Empfehlungen in deutschen Landen viel ernster ausgelegt wurden. Wahr ist jedoch, dass die die Vorgaben, ,Theatralität' und weltliche Instrumente zu vermeiden, der individuellen, subjektiven Interpretation unterlagen. Die elastische syntaktische Formulierung der Botschaft tat dann ein übliches. 
dass die Habsburger, in ihrer seit Jahrhunderten währenden Würde als deutschrömische Kaiser, sich Rom, der römischen Kirche und damit ganz Italien besonders verbunden fühlten. Dies ging mit dem Herrschaftsanspruch in einem universalen, abendländischen, christlich-katholischen Imperium einher; und dieser Anspruch sollte auch in allen zeremoniellen, kulturellen und künstlerischen Bereichen in entsprechender Weise zum Ausdruck gebracht werden. ${ }^{11}$ In der Hofkapelle wurde das italienische Oratorium demgemäß mit einer Devotion zelebriert wie in Italien selbst nur in Ausnahmefällen. Dabei entstand, bekanntlich, auch die spezifische Sonderform des sepolcro: Während gewöhnliche Oratorien in der Fastenzeit ähnlich aufgeführt wurden wie im Mutterland der Gattung, waren die in der Karwoche abgesungenen sepolcri durchaus paraliturgisch angelegt. ${ }^{12}$ Aus diesem Grunde hatten sie stets die Passion zum Gegenstand, auch wenn diese allegorisch bearbeitet und dann halbszenisch, mit dem Grab Christi als Schauplatz, dargestellt wurde. ${ }^{13}$ Zwar kann man zwischen dem 17. und dem 18. Jahrhundert eine kontinuierliche Entspiritualisierung des Wiener sepolcro verfolgen, die dann definitiv in der Verschmelzung mit dem herkömmlichen Oratorium enden sollte, doch war der traditionelle geistliche Gehalt der in der Karwoche in der Hofkapelle aufgeführten Oratorien noch unter Karl VI. außerordentlich groß. Nicht nur orientierten sich die entsprechenden Libretti inhaltlich unverändert an der Passion, aber selbst auf den jeweiligen Titelblättern relativer Werke stand gewöhnlich der Zusatz Azione Sacra al SS. Sepolcro o Componimento Sacro applicato al SS. Sepolcro. ${ }^{14}$

Die Habsburger waren kunstsinnig, zudem außerordentlich religiös, und wenn im Jahr 1740, mit dem Tod von Karl VI., die große Oratorientradition in der Wiener Hofkapelle zu Ende ging, so sind die Gründe eher in der schwierigen Haushaltslage sowie in den politischen Wirren zu suchen, denen sich die junge Thronfolgerin Maria Theresia gegenübersah, als in ihrer mangelnder Devotion. Dennoch ist es ebenso richtig, dass damit in Wien die große Zeit des italienischen Oratoriums in spiritueller Hinsicht endgültig vorbei war. Zwar entstanden an der Donau in der zweiten Hälfte des 18. Jahrhunderts noch einige großartige Werke, doch ihre faktische Bedeutung beruhte auf nunmehr zunehmend künstlerischen Grundlagen, während der geistliche Aspekt allmählich verflachte. Es ist noch

11 RIEDEL, Friedrich W. Kirchenmusik am Hofe Karls VI. (1711-1740). Untersuchungen zum Verhältnis von Zeremoniell und musikalischem Stil im Barockzeitalter. München-Salzburg: Emil Katzbichler, 1977, S. 9-13.

12 GRUBER, Gernot. Das Wiener Sepolcro und Johann Joseph Fux. Graz: Johann Joseph Fux Gesellschaft, 1972.

13 Die Frage der, Darstellung' ist hier keineswegs als streng theatralische Kategorie zu sehen: ist doch die selbige Transsubstantiation in der katholischen Liturgie eine Vergegenwärtigung darstellerischen Ausmaßes.

14 Die Beobachtung gilt etwa auch für Gerusalemme convertita (1733) und San Pietro in Cesarea (1734) von Apostolo Zeno, sowie Sant'Elena al Calvario (1731) und La morte d'Abel (1732) von Pietro Metastasio, um nur jeweils zwei Werke der beiden bedeutendsten Hofdichter zu nennen. 
herauszustellen, dass ein moralischer Anspruch dennoch fortlebte, selbst in den Aufführungen, die sich in die Wiener Adelspaläste verlagerten, aber auf typische Weise gerade in den von der Tonkünstler-Societät organisierten Veranstaltungen zum Zwecke der Wohltätigkeit. ${ }^{15}$

Wenn in Rom und Wien der greifbare Einfluss der katholischen Kirche spürbar auch den geistlichen Gehalt des italienischen Oratoriums durchtränkte, so war die Situation in Neapel denkbar anders. ${ }^{16}$ Die lebensfrohe Stadt am Vesuv hatte eine eigentümliche politische, soziologische, kulturelle und geistliche Ausrichtung. Lange von Spanien dominiert, war sie iberischem Einfluss ausgesetzt, was sich nicht nur in Kultur und Folklore, sondern auch in einer spezifischen Volksfrömmigkeit ausdrückte. Entscheidend war aber eine Freisinnigkeit und letztlich antikuriale Haltung, die intellektuell von Persönlichkeiten wie Giambattista Vico und Pietro Giannone vorangetragen wurde, aber in vielen Bereichen des öffentlichen Lebens einen Niederschlag fand. Bekanntlich wurde der junge Metastasio für sein Dasein von seinen in Neapel empfangenen Eindrücken geprägt ${ }^{17}$. Was das geistliche Ambiente anbetrifft, so ist es aufschlussreich darauf hinzuweisen, dass sich selbst die Oratorianer der parthenopäischen Metropole schon recht früh vom römischen Mutterhaus abwandten - es gab Unterschiede vor allem in der Auslegung des Armutsgelübdes - und auf Selbständigkeit zu pochten. ${ }^{18}$ Dennoch organisierten sie Oratorienaufführungen, oft in Zusammenarbeit mit den vier neapolitanischen Konservatorien, deren Absolventen traditionell mit einem Werk geistlichen Inhalts, sozusagen als Meisterstück, ihr Studium abschlossen. Allerdings handelte es sich dabei nicht um richtige Oratorien, sondern eher um neapolitanische drammi sacri, die nicht nur im lokalen Dialekt abgefasst wurden, sondern auch komische Elemente mit einschlossen. ${ }^{19}$ Das heißt, zwischen Oratorium und dramma sacro ergaben sich zwangsläufig Infiltrationen, was unvermeidlich zu Lasten des tief geistlichen Gehalts ging. Auch deshalb näherte sich das Oratorium in Neapel besonders der Oper an, und es kann nicht verwundern, wenn es mit dem fortschreitenden 18. Jahrhundert immer häufiger szenisch und

15 Die von Florian Gassmann 1771 ins Leben gerufene Tonkünstler-Societät organisierte ihre Akademien zum Wohle von Witwen und Waisen von Musikern und wurde bekanntlich rasch zu einem bestimmenden Faktor im musikalischen Leben der österreichischen Hauptstadt. BASSO, Alberto. L'invenzione della gioia. Musica e massoneria nell'età dei Lumi. Milano: Garzanti, 1994, S. 517 und 522-525.

16 RAO, Anna Maria. Una capitale del pensiero. In COTTICELLI, Francesco-MAIONE, Paologiovanni, ed. Storia della musica e dello spettacolo a Napoli. Il Settecento. vol. I, Napoli: CMA Pietà dei Turchini, 2009.

VALENTE, Mario, ed. Legge poesia e mito. Giannone, Metastasio e Vico fra "tradizione" e "trasgressione" nella Napoli degli anni Venti del Settecento. Atti del Convegno Internazionale di Studi, Palazzo Serra di Cassano, Napoli, 3-5 marzo 1998. Roma: Aracne, 2001.

GASBARRI, Carlo. L'oratorio romano dal Cinquecento al Novecento. Roma: s. e., 1963, S. 75-80.

19 SALVETTI, Guido. Musica religiosa e conservatorii napoletani: a proposito del San Guglielmo d'Aquitania di Pergolesi. Quaderni della Rivista Italiana di Musicologia, 1983, no. 9, S. 207-215. 
sogar in Theatern aufgeführt wurde. ${ }^{20}$ Lediglich zur Zeit der kurz währenden österreichischen Herrschaft zwischen 1707 und 1734 schien es, wohl in Anlehnung an die Wiener Tradition, eine bedeutendere spirituelle Tiefe zu erreichen. ${ }^{21}$ In Neapel war es dem Oratorium also nicht vergönnt, in seiner reinsten Form eine bestimmende Rolle zu spielen; wenn die Stadt zur Entwicklung der Gattung dennoch entscheidend beitrug, so lag es an ihrem wichtigen Anteil an der Herausbildung ihrer entsprechenden musikalischen Sprache, wie an jenen typisch lokalen Impulsen, die auch die Oratoriendichtung Metastasios nachhaltig befruchteten.

Ein grundlegend anderes Bild bietet sich im Falle Venedigs dar, so in soziologischer, ideologischer und kultureller als auch in geistlich-religiöser Hinsicht. Einerseits war die stolze Seerepublik der am meisten prosperierende italienische Staat der frühen Neuzeit, andererseits beruhte ihr Selbstverständnis auf einer Reihe von Widersprüchen, was ihre Verfassung, ihre politische Strategie zwischen Ost und West, sowie ihr oft genug zwiespältiges Verhältnis zur römischen Kirche anbetrifft. Diese versuchte häufig, aber vergeblich, den widerspenstigen Insulanern ihren Einfluss aufzudrängen. Die römische Kurie war ununterbrochen von dem Patriotismus, dem Unabhängigkeitswillen und vornehmlich von der aparten Jurisdiktion der Venezianer irritiert, da diese sich in Anspruch nahm, Entscheidungen auch in kirchlichen Fragen selber zu fällen.$^{22}$ Diese Realität manifestierte sich durch die Autonomie des lokalen Klerus, aber auch dadurch, dass die Geistlichkeit bei Verfügungen, die nur den Staat betrafen, ganz außen vor blieb. Trotz relativer Anstrengungen mehrerer Päpste fuhren die Venezianer fort, kirchliche und staatliche Macht nicht miteinander zu vermengen. Auch war der Heilige Stuhl dadurch beunruhigt, dass in Venedig Bücher erscheinen konnten, die die Kirche wegen ihrer protestantischen oder jansenistischen Inhalte als ketzerisch ansah und auf den Index setzte. Derartige Voraussetzungen mussten sich zwangsläufig auch auf kulturelle Belange im Allgemeinen, sowie auf Pflege und Rezeption einer geistlichen Gattung wie das Oratorium im Besonderen niederschlagen.

Ein charakteristischer Kontrast zeigt sich schon dadurch, dass es in Venedig zwischen dem 17. und dem 18. Jahrhundert zwei verschiedene Oratorienkulturen gab. Die Oratorianer von Venedig richteten an ihrem Sitz, der Kirche Santa Maria della Consolazione - weithin als La Fava bekannt - Aufführungen aus, wie ihre Ordensbrüder in ganz Italien. Weit attraktiver waren allerdings jene Veranstaltungen, die in den vier berühmten Mädchenkonservatorien der Lagunenstadt stattfanden. Bekanntlich waren diese Institutionen kulturell ein Aushängeschild der Seerepublik, nicht umsonst wirkte dort eine Reihe von gefeierten Meistern der

20 CROCE, Benedetto. I teatri di Napoli dal Rinascimento al secolo Decimottavo. Bari: Laterza, 1947, S. 268.

21 Unvergesslich bleiben die Veranstaltungen von 1732 im Königlichen Palast, wobei zwei Meisterwerke von Leonardo Leo, Sant'Elena al Calvario und La morte d'Abel, beide Vertonungen von metastasianischen Texten, zur Aufführung kamen.

ZORZI, Alvise. La Repubblica del Leone. Storia di Venezia. Milano: Rusconi, 1979. 
Epoche als Kapellmeister. ${ }^{23}$ Ihre Aktivität an betreffenden Konservatorien kennzeichnete das erstaunliche technische Können jener jungen Damen, die dort großartige Leistungen als Sängerinnen oder Instrumentalvirtuosen erbrachten. Die musikalische Erziehung war für diese freilich nur Teil einer Allgemeinbildung in christlich-moralischem Sinne, die jedoch spezifische pädagogische Strategien erforderte. Wie es an Jesuitenkollegien geschah, waren die von ihnen aufgeführten, dramatisch angelegten Werke Lehrstücke von grundsätzlich pädagogischem Ansinnen. Dazu gehörte ebenso die rigorose Anwendung der lateinischen Sprache nach bester humanistischer Tradition. Anders als in Rom, war das antike Idiom allerdings nicht Zeichen einer elitären und vergeistigten Entrückung, sondern einfach nur klassische Bildungssprache. ${ }^{24}$

Der Großteil der in den venezianischen Konservatorien aufgeführten Oratorien ging bedauerlicherweise verloren - Vivaldis Juditha triumphans (1716) ist hier eine glückliche Ausnahme - doch sind vielfach gedruckte Libretti erhalten, denen man entnehmen kann, dass sogar metastasianische Oratorientexte ins Lateinische übersetzt wurden, um neu vertont und abgesungen zu werden. Man sollte anmerken, dass die aufführenden Mädchen in der Kirche durch ein Gitter sittsam von der Zuhörerschaft getrennt waren. Diese kam ihrerseits, indessen, mit derselben Erwartung zur Veranstaltung mit der sie sich normalerweise in die Oper begab: Die jungen Künstlerinnen waren bekannt und bejubelt für ihre außerordentlichen Fähigkeiten.

Man sieht an den beobachteten vier repräsentativen Beispielen, dass die Spiritualität des italienischen Oratoriums sich in verschiedenen Ambienten zwar unterschiedlich entfaltete, aber überall weitgehend konstant blieb. Dies gilt vor allem für Rom und Wien; in der kaiserlichen Hauptstadt fand allerdings nach der glorreichen Epoche unter Karl VI. eine Umorientierung statt, die Gattung wurde von den Aristokraten in ihren Palästen gepflegt, um später durch die Aktivität der Tonkünstler-Societät endgültig Bestandteil eines bürgerlichen Konzertwesens zu werden. Der ethisch-moralische, wie auch der devote Anspruch blieb dabei weitgehend unverändert, auch wenn der Weg zur Dekadenz und zur endgültigen Auflösung - aufgrund der gesellschaftlichen und ideologischen Umwälzungen infolge der Aufklärung - unumkehrbar beschritten wurde. Neapel und Venedig bildeten Sonderfälle, am Vesuv war das Oratorium vom Anbeginn weltlich unterwandert, während in der Lagunenstadt eine originelle, pädagogisch ausgerichtete

23 Unter anderen Pallavicino, Gasparini, Biffi, Vivaldi, Porpora, Hasse, Jommelli, Anfossi, Sacchini.

24 Goethe amüsierte sich noch 1786 als er das so italienisch wirkende Latein bei einer Oratorienaufführung bei den Mendicanti hörte: „Die Frauenzimmer führten ein Oratorium hinter dem Gitter auf, die Kirche war voll Zuhörer, die Musik sehr schön und herrliche Stimmen. Ein Alt sang den König Saul, die Hauptperson des Gedichtes. Von einer solchen Stimme hatte ich gar keinen Begriff; einige Stellen der Musik waren unendlich schön, der Text vollkommen singbar, so italienisch Latein, daß man an manchen Stellen lachen muß; die Musik aber findet hier ein weites Feld. "GOETHE, Johann Wolfgang von. Italienische Reise. In Goethes Werke, vol. 10, Berlin-Weimar: Aufbau Verlag, 1981, S. 75. 
Struktur erst durch die napoleonischen Wirren zum Erliegen kam. Wie schon anfangs erwähnt, war die eng mit der Lehre der katholischen Kirche verbundene Spiritualität nur bedingt entwicklungsfähig, und man muss darauf hinweisen, dass die formal-strukturell so ähnliche italienische Oper, die in den letzten Jahrzehnten des 18. Jahrhunderts ebenfalls in einer Krise steckte, sich ihrerseits durchaus reformieren ließ und überlebte, um dann ihren triumphalen Zug ununterbrochen bis ins 20. Jahrhundert fortzusetzen.

Bezüglich Dichtung und Komposition war das italienische Oratorium hingegen einem ähnlichen Entwicklungsprozess ausgesetzt wie sein weltliches Pendant. In literarisch formaler Hinsicht kann man sogar ab einem gewissen Punkt von Parallelismen sprechen, wie es die Gliederung in Rezitativ und Arie und die Behandlung dramaturgischer Elemente hinreichend zeigen. Man sollte aber vorausschicken, dass die literarischen und musikalischen Anfänge der beiden Gattungen ursprünglich unterschiedlicher gar nicht sein konnten: Während die Oper sich an der antiken Tragödie orientierte und sie mit pastoralen Versatzstücken anreicherte, entsprang der Oratorientext der volkstümlichen Laudendichtung, die erst mit der Zeit - über Dialogformen - sich dramatische Strukturen überstreifte. Es ist somit bemerkenswert, dass die beiden Phänomene spätestens nach 1650 formell zusammentrafen. Wie bereits gesagt, stand das Oratorium in der ersten Hälfte des 17. Jahrhunderts noch durchaus dem Jesuitendrama nahe, von dem es allerdings nicht zuletzt durch soziologische Faktoren getrennt wurde.

Es ist angebracht, die lineare Entwicklung des Oratorienlibrettos ab dem Wirken des Literaten Arcangelo Spagna (1632-1726) zu verfolgen. Der römische Kanoniker zeichnet sich nicht nur als Autor von dreißig, etwa zwischen 1656 und 1706 gedichteten Oratorien aus, er muss zugleich als erster und einziger Verfasser eines Traktats über die Gattung hochgeschätzt werden. Sein Discorso dogmatico wurde im ersten Buch seiner 1706 erschienenen Oratorien abgedruckt. ${ }^{25}$ Der gebildete Kleriker skizziert hier einen historischen Abriss des von ihm als melodramma sacro definierten Oratoriums, analysiert es, und spricht sodann wohlbegründete Empfehlungen an seine Dichter aus. Für Spagna ist die Unterteilung in Rezitativ und Arie schon eine Selbstverständlichkeit, und man kann vorwegnehmen, dass die Debora, sein erstes, 1656 entstandenes Oratorium bereits alle wesentlichen formalen Voraussetzungen für eine Vertonung selbst nach den Maßstäben des 18. Jahrhunderts erfüllt. Besonders wichtig ist für ihn die Beibehaltung des Reimes, den er offensichtlich als Garant der literarischen Qualität ansieht. Heftig polemisiert er gegen die Figur des ,Testo', der in älteren Oratoriendichtungen, dem Evangelisten gleich, die Handlung führte und kommentierte; für Spagna ist der Erzähler ein Hindernis für das Selbstverständnis einer dramatischen Form. Er nimmt für sich folglich in Anspruch, diesen selber abgeschafft, zudem auch als erster in die zuvor nur biblische Stoffe aufgreifende

25 SPAGNA, Arcangelo. Oratorii overo melodrammi sacri con un discorso dogmatico intorno l'istessa materia [...] Libro primo, Roma: Gio. Francesco Buagni, 1706. 
Oratoriendichtung die hagiographische Thematik eingeführt zu haben. Von den aristotelischen Einheiten der Tragödie fordert er nur jene der Zeit, doch nicht mit der letzten Konsequenz. Merkwürdigerweise ist er auch ziemlich liberal, was die dichterischen Freiheiten bei der Behandlung eines geistlichen Stoffes betrifft. Allerdings sieht er Würde und Ernst der Dichtung durch verantwortungsvolles literarisches Vorgehen hinreichend gewährleistet.

Spagnas Oratorientexte zeichnen sich durch erstaunlichen Abwechslungsreichtum und durch Buntheit in der Stoffwahl und der dramaturgischen Bearbeitung aus. Dabei scheute er sich keineswegs, sogar mehrfach die ehrwürdigen biblischen Vorlagen zu modifizieren und zu erweitern, zumindest was die Details anbetraf, es reichte, dass der generelle und moralische Ablauf der ,Erzählung' in Einklang mit den christlichen Glaubensinhalten blieb. Und es bleibt durchaus bemerkenswert, dass im strengen Rom die durchaus vorhandenen weltlichen Züge seiner Libretti keinen Anstoß erregten. Offensichtlich war das geistliche Sujet schon an sich sanktionierend, wie es in den bildenden Künsten auch der Fall war. Es bleibt beeindruckend, wie L'Innocenza colpevole, overo la Santa Pulcheria einem klassischen Eifersuchtsdrama gleicht und einzelne thematische Elemente aus Shakespeares Othello heraufbeschwört. Der Schatten des englischen Dramatikers drängt sich gleichermaßen in La Calunnia convinta nella Conversione de' SS. Eugenia, Proto, e Giacinto auf, wo die heilige Protagonistin über weite Strecken in männlicher Gestalt auftritt, sich der Liebesbezeugungen der edlen Dame Melanie erwehren muss, und sich damit unweigerlich in derselben Situation befindet wie die Viola aus Was ihr wollt. ${ }^{26}$ Französische Einflüsse machen sich in anderen Oratorien bemerkbar, so in La Gentilità favolosa nel Martirio di S. Agata, wo die Protagonistin römisch inspirierte heroische Züge zeigt, in scharfem Kontrast zur heuchlerischen Gegenfigur des Präfekten Quintiano. In dieser von Pathos getragenen Dichtung wird die christliche Botschaft effektvoll als Antithese zur heidnischen Sphäre dargestellt; die majestätisch, pathetisch klingenden Verse erinnern auf denkwürdige Weise an Corneille. Dass aus den Oratorien Spagnas selbst ein komischer Zug nicht gebannt war, zeigt gerade Il Trionfo dell'Honestà negl'Auuenimenti della casta Susanna, ein Werk, in dem übrigens auch das erotische Element zum Vorschein kommt. Einem originellen Einfall folgend, lässt der Autor die beiden lüsternen Alten, die Susanne nachstellen, zunächst getrennt ihren Garten betreten, wodurch sich eine Konstellation einstellt, die selbst einer opera buffa würdig wäre. Nach einem possierlichen, doch rhetorisch geschliffenen Dialog agieren die zwei herrlich gezeichneten Greise dann doch zusammen, wie es in der biblischen Vorlage geschieht.

Spagnas Oratorienstil ist für die Epoche um 1700 emblematisch und muss, literarisch betrachtet, auch mit den Zielsetzungen der Arcadia in Zusammenhang gesehen werden. Diese ehrwürdige, 1690 in Rom gegründete Akademie nahm sich

26 Abgesehen davon, dass Shakespeare bei seinen Stoffen auch aus italienischen Quellen schöpfte, konnten englische Vorlagen und Suggestionen von italienischen Schauspielern, die auf der britischen Insel wirkten, bei ihrer Rückkehr in die Heimat importiert werden. 
bekanntlich vor, den schwülstigen Ballast der zeitgenössischen Barockdichtung abzuwerfen und fand ihre idealisierte Symbolik in einem pastoral durchwirkten, antiken Arkadien. Spagna, einer vorhergehenden Generation angehörend, wurde selber zwar nie ,Arkadischer Schäfer', doch unterhielt er nachweislich enge Beziehungen mit vielen Arkadiern. ${ }^{27}$ Und es waren dann auch arkadische Dichter, die das italienische Oratorium weiter veredeln sollten, vor allem die beiden größten Librettisten des 18. Jahrhunderts, die bezeichnenderweise beide in kaiserlichem Dienst standen.

Apostolo Zeno wurde 1718 als Poeta Cesareo nach Wien berufen, war allerdings nicht nur Dichter, sondern auch ein vielseitiger Gelehrter. Der Venezianer hatte zeitlebens ein recht zwiespältiges Verhältnis zu seinen Operndichtungen, die er eher aus finanziell-existenziellen Gründen schrieb. ${ }^{28}$ Hier muss man sich vergegenwärtigen, dass die Arkadier - und Zeno war 1698 eben Mitbegründer der Colonia Arcadica in der Lagunenstadt - die Oper grundsätzlich als etwas scheußliches verwarfen, was allerdings verschiedene Pastori Arcadi nicht davon abhielt, selber Opernlibretti zu verfassen; die hauptsächliche Kritik an der musikdramatischen Gattung war ihre inhaltliche Unwahrscheinlichkeit. Zeno hatte zudem Probleme mit all jenen - nach seiner Ansicht überflüssigen - Elementen wie komische Szenen, Allegorien und auch Götter, die in die Handlung eingriffen. ${ }^{29}$ Konsequenterweise versuchte er diese in seinen eigenen Libretti auszumerzen, wobei er historische Aspekte betonte und sich mehrfach direkt an der französischen Tragödie orientierte. Wie auch immer, es war das Oratorium, in dem er endlich jenes Feld entdeckte, wo er seine eigenen literarisch-dramatischen Vorstellungen realisieren konnte. Dazu lieferte das Ambiente des Wiener Hofes mit seinen entsprechenden Bräuchen natürlich eine ideale Voraussetzung.

Der ,Reichsstil' fand zwangsläufig auch in die für die Hofkapelle bestimmten Werke seinen Eingang. Ein in der Cappella Cesarea abgesungenes Oratorium musste zunächst ein hohes, künstlerisch seriöses Niveau haben, darüber hinaus auch theologisch fundiert sein. Es war zwar keine conditio sine qua non, doch ein willkommenes Attribut, wenn die Handlungen und ihre Personen Bezüge zum Hause Habsburg, oder auch zur aktuellen politischen Lage hatten. Bei seiner Ankunft in Wien 1718 fand folglich Zeno, der zuvor noch nie ein Oratorium geschrieben hatte, eine Tradition vor, mit der er sich sehr schnell identifizierte - wie es bereits sein Erstlingswerk von 1719, der von Giuseppe Porsile vertonte Sisara zeigt. Das Libretto war gespickt von genau angegebenen biblischen und sonstigen theologischen Zitaten, der Einsatz zweier weiblicher Heldinnen, wie Debora und Giaele, nahm unverhohlen auf die schwierige dynastische Situation der Habsburger Bezug und feierte die Erzherzogin Maria Theresia, die laut der Pragmatischen Sanktion (1713) eines Tages die Thronfolge antreten sollte.

\footnotetext{
27 HERCZOG, op. cit., S. 76.

28 Ibid., S. 111-119.

29 Ibid., S. 118.
} 
Zenos insgesamt siebzehn für Karl VI. geschriebenen Oratorien lassen sich in zwei Typen unterteilen: in menschlich-dramatische, wie Tobia oder Giuseppe, und in theologisch- meditative, wie Gerusalemme liberata. Die meisten kamen in der Fastenzeit zur Aufführung, einige andere in der Karwoche, gemäß der in der Zwischenzeit freilich schon unzeitgemäßen Tradition des sepolcro. Konstant blieb der exegetische und auch eschatologische Hintergrund, der mit vielen der Heiligen Schrift, den Kirchenvätern und anderen Theologen entnommenen Belegstellen unwiderlegbar untermauert wurde. Bezüglich der Dramaturgie konnte die in der Oper unverzichtbare sensitive Liebe als Motivation ausgeschlossen bleiben, und so war Zeno überzeugt, mit seinen Oratorien richtige Dramen geschrieben zu haben, die durch nur wenige Änderungen sich leicht in ,gute Tragödien' umgestalten ließen. Das Maßnehmen an der Tragödie war für ihn in der Tat entscheidend, wobei er sich in theoretischer Hinsicht am antiken und in praktischer am französischen Modell inspirierte. Dabei blieb sein dichterischer Stil in den meisten Oratorien allerdings trocken und rhetorisch, eben für ein aristokratisches, gebildetes Publikum bestimmt.

Die Vorliebe Zenos für seine Oratorien wird durch ihre gesonderte, auf eigene Kosten vorgenommene Veröffentlichung unter dem Titel Poesie Sacre Drammatiche offenbart. ${ }^{30}$ Das Vorwort des an das kaiserliche Paar gewidmeten Prachtbandes enthält nun sein oratorisches Credo. Es gibt dabei drei als fundamental herauszustellende Positionen: die Beschränkung auf biblische Stoffe, die sprachliche Orientierung an der Heiligen Schrift, sofern es die Diktion der Propheten und Patriarchen betrifft, und die Beachtung aller drei klassischen, dramatischen Einheiten, das heißt des Ortes, der Zeit und der Handlung. Der Kanon, der hier verkündet wird, lässt sich dann in weitgehend allen azioni sacre Zenos - wie er selbst auch häufig seine Oratorien nannte - positiv nachvollziehen.

Die Existenz der zenoschen Oratorien ist eigentlich dem glücklichen Zusammentreffen dreier grundlegender Voraussetzungen zu verdanken: der typischen Tradition und Erwartung am Wiener Hof, der starken Religiosität desselben Venezianers, und schließlich seinen schon erwähnten eigenen dramatischen Ansprüchen, die nach seinem Dafürhalten nur im Oratorium realisiert werden konnten. Die genau umschriebene Funktion in der kaiserlichen Kappelle war natürlich ein kausaler Ausgangspunkt, und die angewendeten Mittel wurden auf jeden Fall aus den philosophischen und literarischen Errungenschaften der Zeit geschöpft: die gewissenhafte Absicherung durch Zitate aus biblischen, kanonischen und sonstigen theologischen Schriften, und die starke Tendenz zum rhetorischen und argumentativen Stil scheinen durchaus jenem rationalistischen Humus entnommen, der sogar in konservativen Kreisen Wirkungen zeigte, und dem sich selbst der devote Katholik Zeno nicht entziehen konnte. Bleibt allerdings die Exklusivität der entsprechenden Werke, die außerhalb des Wiener Hofes nur sehr selten vertont wurden. ${ }^{31}$ Andererseits gilt es als sicher, dass diese der zeitgenössischen

31 Die wenigen, nicht immer gesicherten Ausnahmen wären La Gerusalemme convertita (1751) 
literarischen Elite sehr wohl bekannt waren, und sei es eben durch die Veröffentlichung der Poesie Sacre Drammatiche. Abschließend muss man genauso konstatieren, dass die zenoschen azioni sacre ein direktes Vorbild für jene Metastasios darstellten, in denen wir die dichterische Vollendung und letzte literarische Blüte des italienischen Oratoriums erkennen müssen.

Wenn Metastasio als der größte italienische Dichter und Librettist des 18. Jahrhunderts eingeschätzt werden muss, so liegt dies vor allem an der Eleganz und der Musikabilität seiner Verse - Eigenschaften, die im Falle seines eben besprochenen großen Vorgängers am Wiener Hof nur in bescheidenerem Ausmaß anerkannt werden können. Zwar war der Römer Abbé und Arkadier, doch gleichzeitig auch eine mondäne Persönlichkeit von äußerst geschliffenen Umgangsformen. ${ }^{32}$ Dass er als typischer Repräsentant des arkadisch-rationalistischen Geistes gelten kann, erklärt sich zunächst aus der Unterweisung durch seinen Mentor und Vormund, den großen Gian Vincenzo Gravina, dann aber auch aus seinen in Neapel verbrachten Jahren, die den jungen Mann entscheidend formten. Im Gegensatz zu Zeno war das Verhältnis des jüngeren Dichters zu seinen Opernlibretti rundum positiv; bekanntlich wurden diese von den besten zeitgenössischen Komponisten vertont, einzelne Texte bis zu dreißig Mal, so dass es angemessen erscheint, im Zusammenhang mit der italienischen Oper für den größten Teil des 18. Jahrhunderts von einem metastasianischen Zeitalter zu sprechen.

Man darf vorwegnehmen, dass für den Römer die Oratoriendichtung in Wien eher als lästig erschien. Dies hat einerseits damit zu tun, dass das Abfassen eines Oratoriums in der von Zeno vorgezeichneten Weise - die der junge Nachfolger unbedingt beachten musste - ein aufwendiges, zeitraubendes Studium der Bibel und anderer theologischer Quellen erforderte. Doch war für ihn die Skepsis auch moralisch, ästhetisch und dramaturgisch begründet. Viele Erzählungen aus der Bibel, die für ein Oratorium verarbeitet werden konnten, waren durch ein fragwürdiges, oder gar unmoralisches Vorgehen des Helden, oder der Heldin, gekennzeichnet. Schon Abrahams Bereitschaft, den eigenen Sohn zu opfern, wirkt verstörend; man denke an Jakob, der nicht nur auf eine heimtückische Weise das Erstgeburtsrecht seinem Bruder Esau abkauft, sondern dann auch seinen Vater Isaak arglistig täuscht; oder an Judith, die sich bei Holofernes einschleicht, dessen Gastfreundschaft genießt, und ihn dann brutal köpft. In der metastasianischen Oper waren die Tugend und das unvorhersehbare Schicksal die Triebfeder der Handlung, im Oratorium musste es der nicht anzweifelbare, statische göttliche Wille sein, im Einklang mit dem katholischen Dogma. Auch war das totale Fehlen von sensueller Liebe und sinnlich liebenden, entschlossenen Heldinnen

von Galuppi, Gerusalemme convertita (1755) von Jommelli und Gesù presentato al tempio (1761) von Sacchini. Der Joaz (1726) von Benedetto Marcello wurde zwar in Venedig, aber für Wien komponiert, dort jedoch nie aufgeführt.

32 BRUNELLI, Bruno. Pietro Metastasio. In BRUNELLI, Bruno, ed. Tutte le opere di Pietro Metastasio. Milano: Mondadori, 1953, vol. I, S. XI-XLIX. 
- Schlüsselfiguren in der metastasianischen Dramaturgie - im Oratorium der Gestaltung des Handlungsablaufs abträglich. ${ }^{33}$

Dennoch schrieb Metastasio für die Hofkapelle sieben großartige Oratorien, die nicht nur den Gefallen des Kaisers zu erwecken vermochten, sondern dann von vielen Komponisten vertont wurden: ein Privileg, das den auf nur Wien beschränkten azioni sacre Zenos verwehrt blieb. Dabei folgte der jüngere Dichter bezüglich der dramaturgischen Anlage äußerst fügsam dem vom großen Vorgänger gewiesenen Weg, wie es die Gegenüberstellung je zweier Werke gleicher Thematik aufschlussreich belegt; es handelt sich um Giuseppe (1722) und Giuseppe riconosciuto (1733) beziehungsweise um Gioaz (1726) und Gioas re di Giuda (1735). Zwar ist es richtig, dass Metastasio in seinem Gioas ein intreccio - opernhafte Verwicklung - in die Handlung einbaut, der bei Zeno undenkbar wäre, doch besteht der Hauptunterschied in der Charakterisierung der Personen, vornehmlich in der auffälligen Akzentuierung des weiblichen Elements. Dies letzteres konnte freilich, angesichts des Fehlens männlicher Nachfolger Karls VI., sogar auf günstige Aufnahme in der kaiserlichen Familie treffen, aber Metastasio entwarf Frauengestalten, die üblicherweise eher in seinen melodrammi beheimatet waren.

Es ist schon eindrucksvoll, die schleichende und konstante ,Melodrammatisierung' in der Abfolge der metastasianischen Oratorien gerade anhand der Entwicklung der weiblichen Figuren zu beobachten. Schon die Maddalena im Erstlingswerk La Passione di Gesù Cristo (1730) zeigt außergewöhnliche Emotionen, und die Protagonistin in Sant'Elena al Calvario (1731) gebärdet sich wie eine stark fühlende Frau. Eva in La morte d'Abel (1732) ist eine richtige metastasianische Mutter, mit all ihren Ängsten und Zweifeln. In Giuseppe riconosciuto (1733) ist nicht nur die Gattin des Helden Aseneta - genuine sposa - eine kluge Frauenfigur, überhaupt schwebt über dem ganzen Geschehen ideell die Mutter Giuseppes und Beniaminos, die liebreiche Rachele, als dramaturgischer Knotenpunkt. Betulia liberata (1734) bildet in diesem Zusammenhang eine Ausnahme, da Metastasio moralische Bedenken über das Vorgehen Giudittas hatte; ${ }^{34}$ dennoch bleibt es bezeichnend, dass in diesem Oratorium eine couragierte Frau die belagerte Stadt rettet. In Gioas re di Giuda (1735) müssen wir das vielleicht opernhafteste metastasianische Oratorium erkennen: das schon erwähnte intreccio zieht die Mutter des Prinzen Gioas in die Handlung ein, die in der entsprechenden biblischen Vorlage gar nicht vorkommt. Sara in Isacco figura del Redentore (1739) durchlebt schließlich mit übersteigerter theatralischer Verve all die Leiden einer geprüften Mutter.

Der Prozess der allmählichen Annäherung an die Oper ist also jener Faktor, der die denkwürdige Entwicklung des metastasianischen Oratoriums bestimmt. Es ist interessant, zu bedenken, dass sich hier in der Geschichte der dichterischen Konsolidierung der Gattung ein Kreis schließt. Bereits Spagna sprach in seinem

33 HERCZOG, op. cit., S. 185-190.

34 Ibid., S. 188. 
Discorso dogmatico von einem perfetto melodramma spirituale, und er hatte nie Ängste vor einer eventuellen Verweltlichung durch die Verwendung von formalen und literarischen Kriterien, die vom Theater herrührten, wenn das geistliche Sujet und ein guter Geschmack in der Bearbeitung Garanten der Spiritualität blieben. Zudem gilt es zu bedenken, dass das Oratorium sich ursprünglich an das einfache Volk wenden sollte und nicht an ein intellektuelles, elitäres Publikum. Diese Prämisse wurde durch die Oratoriendichtung Metastasios auf wunderbare Weise erfüllt: die Texte des Römers fanden bei Aristokraten und bei Bürgern gleichermaßen Anklang, und die Komponisten selbst nahmen sich ihrer begeistert an, wobei sie die grundsätzlich musikalische Gattung zu ihrer eigentlichen Bestimmung führten.

Natürlich wirkten im 18. Jahrhundert zahlreiche andere hervorragende Librettisten, die zur allgemeinen Oratoriendichtung gleichermaßen ausgezeichnete Werke beisteuerten. Doch um die entsprechende poetische Entwicklung linear darzustellen, bot es sich an, den relativen Prozess anhand der drei kommentierten Dichter zu beobachten; umso mehr, als diese nicht nur als emblematisch für die Evolution des Oratorientextes angesehen werden müssen, sondern darüber hinaus auch Modellcharakter für zeitgenössische Strömungen hatten. Vor allem Metastasios Stil wurde von vielen Librettisten imitiert. Jedenfalls handelt es sich hierbei um einen organischen Verlauf, im Einklang mit der universal geistesgeschichtlichen und der spezifisch literarischen Fortentwicklung in Europa, beziehungsweise in Italien. Ein ähnlicher, fortlaufender Mechanismus entfaltete sich beim musikalischen Werdegang der Gattung.

Im Gegensatz zur verwandten Oper sind die Ursprünge des Oratoriums keineswegs in der Monodie zu erfassen, sondern vielmehr in der zwar schlichten, aber doch mehrstimmigen Laudenkomposition. Erst die formale und technische Annäherung der beiden Gattungen sollte analoge morphologische Lösungen zur Folge haben. Die generelle kompositionstechnische Entwicklung zwischen dem 17. und dem 18. Jahrhundert schlägt sich mithin in beiden Fällen grundsätzlich vergleichbar nieder, selbst wenn für die auch satztechnisch bedingte Tonsprache der späteren opera buffa im Oratorium sich kaum eine Entsprechung findet. Die maßgebliche strukturelle Änderung im angegebenen Zeitraum ist notorisch der Übergang vom Generalbass zum oberstimmenorientierten Komponieren, ein Umschlagen der Parameter, das in Italien und nach traditioneller Auffassung vor allem in Neapel eingeleitet wurde. ${ }^{35}$ Auch wenn es sich um einen schwer fassbaren, da sich ständig in Bewegung befindenden Prozess handelt, kann man zwei Punkte als relativ sicher bezeichnen. Erstens entstand die neue Kompositionsweise, in der der schreitende Bass in pochende Einzelnoten aufgelöst wurde, wohl im Zusammenhang mit der komischen Oper, und zweitens ist ihr Eindringen, etwa

35 HELL, Helmut. Die neapolitanische Opernsinfonie in der ersten Hälfte des 18. Jahrhunderts. Tutzing: Hans Schneider, 1971. 
zwischen den zwanziger und dreißiger Jahren des 18. Jahrhunderts, auch in der opera seria festzumachen.

Der neue Stil, den man dann nach seiner Konsolidierung gewöhnlich mit dem Idiom der musikalischen Klassik identifiziert, sah in der Melodie den prinzipiellen Ausgangspunkt der Komposition, während der Generalbass sich in seinen Anfängen noch an ein artifizielles, harmonisch auf Intervallkombinationen basiertes Konzept anschloss, das seit dem Mittelalter bis zur Vokalpolyphonie der Renaissance eigentlich stets Gültigkeit behielt. Trotz bekannter Fortentwicklungen, im sogenannten Generalbasszeitalter wurde die Essenz des Satzes immer in der fortschreitenden Bassstimme konzentriert, die schon für sich genommen grundlegende strukturelle Elemente einer vorliegenden Komposition enthielt, so auch deren Harmonik. In der klassischen Schreibweise hingegen wird die harmonische Fortschreitung von der Melodie vorgegeben, was übrigens auch erklärt, weshalb zwischen barocken und klassischen Melodien unvermeidlich substantielle Unterschiede bestehen müssen, mit Konsequenzen für die ganze musikalische Struktur. Der wichtigste ist dabei wohl, dass die Harmonik in der klassischen Schreibart sich horizontal fortentwickelt, in klarem Gegensatz zur vertikalen Ausrichtung im Generalbasssatz. Wenn freilich beim Generalbass die harmonische Fortschreitung punktuell, das heißt schrittweise erfolgte, so musste sie im klassischen Satz sich horizontal ausbreiten und eben von der Metrik geordnet werden, auch durch die ständige Wiederkehr von regulären Kadenzen. Die kadenz-metrische Einrichtung sollte dann ebenso zur Bildung der achttaktigen klassischen Perioden führen, bestehend aus jeweils viertaktigem Vordersatz und Nachsatz. Der tonale Zusammenhang glitt vom Bass in den musikalischen Satz hinüber und wurde dort durch lange, meist den Bläsern anvertraute Haltenoten als Achse realisiert.

Der Übergang zwischen den beiden Satztechniken war natürlich graduell, ist aber auf jeden Fall nicht nur in der italienischen Oper, sondern auch im italienischen Oratorium klar zu verfolgen. Dessen musikalische Gewandung durchläuft alle entsprechenden Stadien von der Frühzeit des Generalbasszeitalters, über dessen Reife und Auflösungserscheinungen, bis hin zur ersten zaghaften Erscheinung der oberstimmenorientierten Komposition, schließlich derer endgültigen Durchsetzung und ihrem ultimativen Triumph in der Wiener Klassik. In Werken des späten 17. Jahrhunderts, etwa von Bernardo Pasquini oder Giovanni Legrenzi, lassen sich sogar noch Archetypen der klassischen Sprachdeklamation entdecken, ein Verhalten das von Spagna, ästhetisch dem recitar cantando verpflichtet, ausdrücklich gefeiert wurde. ${ }^{36}$ Stand hier ein sorgfältig ausgearbeitetes Rezitativ anfänglichen, einfachen Arienformen gegenüber, so renkt sich bei Alessandro Stradella und Alessandro Scarlatti ein Gleichgewicht ein, in dem Rezitativ und Arie sich in der Waage halten, wobei allerdings rein musikalische Techniken, wie das Konzertieren, auch in den Vordergrund rücken. Reife Generalbassstruktur präsentiert sich in den singulären Oratorien des jungen Händel in Rom, beziehungsweise des vielseitigen Vivaldi in Venedig. Sowohl La Risurrettione di 
Nostro Signor Giesù Cristo (1708) des ersten, als auch die Juditha triumphans (1716) des zweiten enthalten großartige Momente, in voller Entsprechung der musikhistorischen Tragweite ihrer Schöpfer.

Die Fälle Vivaldis und Händels zeigen allerdings auch, dass große Künstler, trotz ihrer allgemein anerkannten Genialität, nur bedingt als Vertreter genereller stilistischer Evolution erachtet werden können, die andererseits mit größerer Objektivität in den Werken sogenannter ,kleiner Meister' festzumachen wäre. Dieselbe Bemerkung gilt in gewisser Weise auch für den vielleicht wichtigsten musikalischen Repräsentanten des italienischen Oratoriums überhaupt: Antonio Caldara. Der Venezianer war einer der berühmtesten Komponisten seiner Zeit und in Diensten des ihn außerordentlich bewundernden Karls VI. in Wien. Seine Oratorien lassen verschiedene Stile erkennen: während er in Venedig und in Rom den galanten Tendenzen der Zeit noch äußerst aufgeschlossen gegenüberstand, musste er in Wien sich einer konservativen Schreibart zuwenden, so verlangte es die ehrwürdige Tradition der Hofkapelle, aber auch der persönliche Geschmack des Kaisers. ${ }^{37}$ Deshalb werden die zahlreichen Wiener Oratorien von Caldara - und er war es gewöhnlich, der die Libretti Zenos und Metastasios überhaupt zum ersten Mal in Musik setzte - von akademischen, imitativen Instrumentaleinleitungen eröffnet und ebenso von dichten, langen Chören abgeschlossen. Auch die einzelnen Arien strotzen von freilich großartigen, besonders fantasievollen kontrapunktischen Lösungen. Für die relativen Vertonungen gilt damit dasselbe wie für Zenos azioni sacre: sie waren spezifisch, sozusagen exklusiv, für das aristokratische, christlich-absolutistische Ambiente des kaiserlichen Hofes bestimmt. Doch muss man festhalten, dass Caldara in seiner Jugend viel Kühnes geschaffen hat; die möglicherweise noch im ausklingenden 17. Jahrhundert für Venedig geschriebene Maddalena ai piedi di Cristo zeigt nicht nur einen außergewöhnlichen Stock von raffinierten kompositorischen Techniken, sondern beeindruckt auch durch eine bestürzende Affektivität, die durchaus schon an eine Art Romantik ante litteram denken lässt. Ferner ist es ebenso richtig, dass Caldaras Wiener Oratorien - trotz ihrer konservativen Machart - doch vielfach eine vorsichtige Lockerung der Generalbassstruktur vorweisen, wie man es aus blockhaften Bildungen und sogar wohldosiert pulsierenden Bässen ersehen kann. Schließlich kam der Stimmigkeit seines Satzes auch das typisch venezianische Erbe einer satten Sonorität adäquat zugute, die insgesamt auch die horizontale Ausrichtung der Harmonik förderte.

Die kompositorische Fortschrittlichkeit in der ersten Hälfte des 18. Jahrhunderts war klar eine Domäne der sogenannten neapolitanischen Schule, auch wenn sich die Neuerungen sehr bald panitalienisch gestalteten. Doch schien die betörend expressive Kantabilität, die sich am Vesuv entfaltete, von besonders katalytischer Wirkung zu sein. Die Entwicklung wurde durch eine Reihe von exzellenten Komponisten vorangetrieben, die man praktischerweise in drei Generationen un-

37 KIRKENDALE, Ursula. Antonio Caldara. Life and Venetian-Roman Oratorios. Firenze: Leo S. Olschki, 2007, S. 396-397. 
terteilen kann. Meister wie Leonardo Leo, Leonardo Vinci und Giovanni Battista Pergolesi waren also die ersten, in deren Partituren der Bass zu pulsieren begann. Vor allem Leo, der sowohl der für die Oper bestimmten, modernen Satztechnik als auch des in der Kirchenmusik beheimateten stile antico mächtig war, wird in diesem Zusammenhang zu einer führenden Figur. Seine beiden, wohl 1732 entstandenen metastasianischen Oratorien, die Sant'Elena al Calvario und La morte d'Abel, gehören zweifellos zu den besten der Gattung, die je geschrieben wurden; und für das dritte Jahrzehnt des Jahrhunderts enthalten die beiden Werke unerhört Modernes. Zum ausdrucksvoll neapolitanischen Melos gesellt sich ein neues kompositorisches Verfahren, das in verschiedenen Komponenten begriffen werden kann. Vor allem ist das Pulsieren im Bass ganz anders als gelegentlich bei Vivaldi, Händel und Caldara, da es sich nunmehr im Kontext mit kadenz-metrischen Passagen realisiert. Es formt sich auch eine horizontale Strukturierung durch regelmäßige achttaktige Perioden; die mitten in die Textur verlegten langen Haltetöne gestalten eine tonale Achse; und es gibt Abschnitte, in denen der Bass keine Bedeutung mehr hat, oder ganz und gar fehlt. Schließlich wird auch der Kontrast zwischen Forte und Piano strukturell verwendet und ,komponiert'. Die aufgezählten Symptome erscheinen in den beiden Partituren fürs erste natürlich nur singulär. Ähnliches lässt sich über die Kompositionsweise von Vinci und Pergolesi sagen: dabei war Leo gelehrt, Vinci ungestüm, Pergolesi eher originell. Jedenfalls war die musikalische Sprache der drei Meister von charakteristisch neapolitanischer Melancholie wie auch von vorwärtsdrängender Dynamik durchdrungen. Bei der Bildung ihrer Melodien spielte der Dreiklang eine tragende Rolle, der Satz wurde zunehmend transparent. Gewiss waren sie nicht die einzigen, die den neuen Stil prägten, aber auf jeden Fall die auffälligsten.

Für die zweite Generation neapolitanischer Meister war das junge musikalische Idiom schon eine Selbstverständlichkeit, in ihren Partituren sind die Generalbassstrukturen zumeist schon vollständig überwunden, werden höchstens gezielt eingesetzt, um bestimmte inhaltliche Gegebenheiten treffend zu unterstreichen. Der deutsche Neapolitaner Hasse schrieb Partituren von imposanter Durchsichtigkeit und Eleganz, der drängende Duktus wird durch strukturelle Feinheiten angereichert, die öfters auch der Steigerung des Ausdrucks dienen. In diesem Sinn wären seine instrumentalen Begleitfiguren zu verstehen, in denen metrisches Ebenmass, auch Chromatismen und Durchgangsdominanten an der Interpretation des Textes Anteil nehmen. Das heißt, dass das orchestrale Gewebe sich anspruchsvoller gestaltet und dennoch in einem wohlproportionierten Gleichgewicht verbleibt, so zum Beispiel auch im Daniello (1731) und im Giuseppe riconosciuto (1741), Oratorien deren Libretti von Zeno, respektive Metastasio verfasst wurden.

Bezeichnenderweise war Hasse der bevorzugte Komponist Metastasios; der ,Sassone' pflegte eine anmutige, affektvolle Tonsprache voller technischer Kostbarkeiten, doch nicht zu schwer, um die Aufmerksamkeit des Zuhörers vom Drama abzulenken. Aus diesem Grunde war der Dichter vielleicht nicht immer glücklich über die großartigen Lösungen des - von ihm übrigens ebenso verehrten und hofierten - Jommelli. Dieser interessierte sich schon etwas zu sehr für 
genuin strukturelle musikalische Fragen, wobei er allerdings vielleicht als erster der sich eben konsolidierenden klassischen Tonsprache eine autonome kompositorische Substanz verlieh. In seinen Partituren lassen sich in der Tat schon vorzeitig Elemente ausmachen, die von der metastasianischen Ästhetik abrücken: Diese beruhte ja auf einem Primat des Wortes, das der Musik kein Eigenleben zugestand, nur die Funktion, die Dichtung auf delikate Weise zu transportieren. ${ }^{38}$ Ironischerweise war Jommelli aber ein hervorragender Musikdramaturg, stets auf der Suche, der dramatischen Situation einen entsprechenden musikalischen Ausdruck zu geben. Dass sich in seinen Werken musikalische Dramatik und musikalische Autonomie gegenseitig nicht unbedingt ausschließen müssen, lässt schon unvermeidlich an den künftigen Mozart denken. Einzelne Worte und Passagen werden syntaktisch vertont, und es zeigt sich auch eine Tendenz für durchkomponierte Lösungen, die ebenfalls zukunftsträchtig sind. Auch findet sich in der Musik des erfindungsreichen Meisters ein Verbindungsglied zwischen der neapolitanischen Opernsinfonie aus der ersten Hälfte des 18. Jahrhunderts und der späteren Sinfonie der Wiener Klassiker. Unter seinen zahlreichen Oratorien sollte man vor allem die metastasianische Passione di Gesù Cristo (1749) hervorheben.

Galuppi war zwar Venezianer, doch bildet er zusammen mit Hasse und Jommelli eine Art Triumvirat. Seine bestechende Dynamik und seine melodische Erfindung veredeln sich durch eine verfeinerte Harmonik, die schon immer ein Kennzeichen seiner Heimatstadt war; und die geschickt eingefügten Alterationen dienen häufig ebenfalls dem außergewöhnlichen horizontalen Drängen. In seinem Adamo caduto (1747) sind sowohl Kantabilität als auch deklamatorische Momente zu bewundern, wobei die gleichzeitige Autonomie des Orchesters eindrucksvoll in die Zukunft weist.

Die Partituren von Hasse, Jommelli und Galuppi stellen den Entwicklungsstand der italienischen Komposition gegen Mitte des 18. Jahrhunderts im besten Lichte dar. Es handelt sich um den modernsten Stil überhaupt, das Verlassen der Generalbasstechnik ist vollzogen. Das grundsätzliche technische Rüstzeug der drei Meister ist weitgehend identisch, wurde von diesen allerdings, je nach persönlichem Geschmack, mit individuellen Finessen angereichert. Die folgende Generation verkörpert schließlich die letzte Blüte der großartigen Entwicklung, bevor sie von den Wiener Klassikern angenommen und weitergeführt wird. Zugegeben zeigt freilich der betreffende Zeitabschnitt in der zweiten Hälfte des Jahrhunderts schon Anzeichen von Routine und Manierismus. Wieder sind es drei Komponisten unter vielen, deren Schaffen einen aufschlussreichen Einblick in den Stand der relativen Oratorienkomposition gewähren, wobei die jeweilige Opernerfahrung des einzelnen auch eine konstituierende Rolle spielt.

Bei Piccinni wird das Oratorium endgültig opernhaft. Zwar sind die ersten Werke des Meisters, wie auch der metastasianische Gioas rè di Giuda (1752),

38 Metastasio kritisierte schon Caldara, von dem er sagte, zwar ein berühmter Meister des Kontrapunktes, aber im Ausdruck und im Bemühen um das Angenehme übertrieben nachlässig gewesen zu sein. HERCZOG, op. cit., S. 283. 
mit ihrer linearen Faktur musikalisch noch ganz der Tradition verpflichtet. Doch der viel spätere Gionata (1792) gehört bereits einer anderen Epoche an. Der Fakt, dass dieser für das Teatro di San Carlo bestimmt war, spiegelt sich nicht nur in der szenisch geplanten Anlage, sondern auch in der selbigen Komposition. Die sensible Erweiterung des Orchesters und das Einfügen von Märschen und Chören - die nichts mehr mit den traditionalen Schlusschören in Oratorien zu tun haben - sprengen die Grenzen der ehemals intimen Gattung. Die Überdehnung ist sicherlich mit jenen Reformbestrebungen zu erklären, in die die italienische Oper damals zur Überwindung des metastasianischen Modells verwickelt war.

Piccinni selbst war in den französisch-italienischen querelles in Paris involviert, auch sein exzellenter Kollege Sacchini wirkte zeitweise in der französischen Hauptstadt. Dort empfing er vielleicht jene dramatische Verve, die sich in seinen Kompositionen, sowohl durch eine Sturm-und-Drang-Haltung, als auch überraschenderweise durch eine an Gluck mahnende musikalische Sprache bemerkbar macht; letztere wäre sicherlich gemeinsamen Visionen und Konzepten, nicht etwaigem Nacheifern zuzuschreiben. Wie viele italienische Komponisten, lässt auch Sacchini manchmal an Mozart denken, der natürlich ein dankbarer Empfänger von Impulsen aus dem Süden war. Der authentischste Vorläufer des Salzburgers war jedoch ohne Zweifel Anfossi. Vielleicht war es seine lange Erfahrung als Violinist in Neapel, der ihm eine besondere Sorgfalt bei der Orchesterbehandlung bescherte, jedenfalls ist in seinen Werken die typische Tonsprache der Zeit mit auffällig vielen Konstruktivismen verbrämt. Diesbezüglich führt er weiter fort, was schon bei Jommelli spürbar war. In ihm verfestigt sich das klassisches Konzept in beachtlichem Maße, wenn man die Ausgewogenheit konstituierender Elemente ins Auge fasst. Hier vereinen sich ein alternierend drängender und zarter Duktus mit origineller Behandlung der melodisch strahlenden Singstimmen und dem bis ins letzte Detail kultivierten Orchestersatz. Hervorzuheben wäre schließlich das trotzdem noch bestehende Gleichgewicht zwischen Dichtung und Musik, wie es in der römischen Fassung seines Giuseppe riconosciuto (1776) in musterhafter Weise realisiert wird.

Mit der Generation der drei zuletzt besprochenen Komponisten erfüllt sich das letzte große Kapitel in der Geschichte des italienischen Oratoriums. Wohl wurden entsprechende Werke noch bis ins 19. Jahrhundert geschaffen, ihre Faktur und ihre Rezeption bildeten aber einen starken Kontrast zum ehedem ehrwürdigen Selbstverständnis der Gattung. Zu erwähnen wären freilich noch die relativen Unternehmungen der beiden Wiener Klassiker Haydn und Mozart. Letzterer schrieb seine Betulia liberata (1772) mit sechzehn Jahren, auf Bestellung in Italien; ${ }^{39}$ die Vertonung der metastasianischen Vorlage ist großartig, zeugt von den bekannten Fähigkeiten des noch jungen Komponisten, der hier das Beste von sich gab. Das Gelingen des Werkes war allerdings dadurch garantiert, dass das Wunderkind noch nicht die volle Reife der späteren Jahre besaß, so wurde die Dichtung nicht durch übermäßige kompositorische Dichte überrollt. Haydn hin- 
gegen komponierte seinerseits Il ritorno di Tobia (1775) schon als reifer Meister, allerdings von vornherein für die bürgerlich ausgerichtete Benefizveranstaltung der Tonkünstler-Societät. ${ }^{40}$ Auch dieses Oratorium gehört zweifellos zu den hervorragendsten, die je geschrieben wurden, das von Giovanni Boccherini - Bruder von Luigi - abgefasste Libretto ist sogar durchaus metastasianisch inspiriert. Das im Kärntnertortheater aufgeführte Werk hatte alle Attribute eines großangelegten, auf Wirkung zielenden Konzerts, mit zahlreichen Mitwirkenden und konzertierenden Einlagen zwischen den beiden Teilen. Das Oratorium selbst war sehr lang, so dass Haydn die ausgedehnten Arien für eine Aufführung neun Jahre später im Hofburgtheater empfindlich kürzen musste - allerdings fügte er, unter dem Eindruck des sich gerade zu jener Zeit verbreitenden händelschen Modells, ebenso zwei neue Chöre hinzu, die dann vom Publikum begeistert aufgenommen wurden. Kompositorisch betrachtet ist Il ritorno di Tobia sicherlich das einzige italienische Oratorium überhaupt, das den technischen und ästhetischen Anforderungen der Wiener Klassik voll gerecht wird: Die angewandten Techniken von Spaltklang, Mischklang und durchbrochener Arbeit - um nur einige zu nennen - scheint Normalität, und man sollte bedenken, dass Haydn 1772 schon fast die Hälfte seiner Sinfonien, darunter auch einige wichtige, vollendet hatte.

Eine gesonderte Betrachtung der jeweiligen Entwicklungsstränge der konstituierenden Faktoren des italienischen Oratoriums bestätigt abschließend das bereits eingangs implizierte chronologische Auseinanderdriften derselben. Es bleibt außer Frage, dass die Spiritualität der Gattung zwischen dem 17. und dem 18. Jahrhundert grundsätzlich stabil blieb, wenn auch die Akzentuierung einzelner Glaubensinhalte, auch in Übereinstimmung mit zeitgenössischen ideologischen Strömungen, leichte Abwandlungen erfuhr. Lokale Gegebenheiten waren dabei ebenso von entscheidender Bedeutung. Ein entsprechender Umbruch, gerade an der Schwelle der französischen Revolution, lässt sich - schon aus librettistischer Sicht - nicht leugnen, wird auch durch die Veränderung des Rezeptionsverhaltens seitens der Zuhörer bescheinigt. Der Werdegang des italienischen Oratoriums in Wien ist hier besonders aufschlussreich. Die unter Kaiser Karl VI. noch elitäre, intime und paraliturgische geistliche Praxis, die sich auch auf die Beschaffenheit relativer Werke niederschlägt, hört mit dessen Tode 1740 schlagartig auf, und die Pflege der Gattung wandert ab in die Adelspaläste. Dies bewerkstelligt eine Tradition, die übrigens gleichzeitig auch in Rom - optional aber nicht ausschließlich - noch gültig war. Mit der Gründung der Tonkünstler-Societät 1771 wird das Oratorium, verbürgerlicht', in Theatern finden Benefizvorstellungen statt, die aufgeführten Werke zielen auf Masseneffekt. Dies ist vor allem dem Siegeszug des händelschen Modells auf dem Kontinent zuzuschreiben, das mit seinen mitreißenden Chören eine eigene Dynamik entfaltete. Damit wird auch klar, weshalb Mozart, als er 1785 zur Beisteuerung eines Werkes gebeten wurde, seinen ursprünglichen Plan, das bis dahin vielleicht noch nie aufgeführte Jugend- 
werk Betulia liberata darzubieten, rasch fallen ließ und lieber die Parodie seiner c-Moll Messe (KV 427), den Davidde penitente ablieferte. ${ }^{41}$ Die Veranstaltungen der Tonkünstler-Societät waren spektakuläre Konzerte für ein möglichst großes Publikum, nicht spirituell, doch ihr moralischer Ansatz im Zeichen der Wohltätigkeit war garantiert. Hier muss man bedenken, dass Händels Oratorien in London oft auch in Benefizveranstaltungen dargeboten wurden, wenn man nur die jährlichen, 1750 noch vom Autor ins Leben gerufenen Aufführungen des Messias im Foundling Hospital erwägt.

Die Entwicklung des Oratorienlibrettos ist unter sowohl literarisch-formalen als auch inhaltlich-ideologischen Gesichtspunkten zu bewerten. Die Komplexität des Prozesses ist auf jeden Fall größer als vergleichsweise im Falle der Oper. Auf den einfachsten Nenner gebracht spiegelt selbst die Oratoriendichtung in ihrer Evolution einen sanften Übergang vom barocken Fideismus zum voraufklärerischen Rationalismus. Spagnas Glaubenssätze erweisen sich noch als felsenfest, auch deshalb ist es sensationell und zukunftsweisend, wenn in La Vittima innocente nel Sacrificio della Figlia di Iefte der Freundin der unglücklichen Tochter Jeftes ein verzweifeltes In-Frage-Stellen des göttlichen Willens - verschämt als „Himmel' umschrieben - entfährt, worauf der Chor sie allerdings zurechtweist und lapidar zum Schweigen verurteilt. Zeno war ebenfalls gläubiger Katholik und schrieb seine Texte für die Untermauerung des katholischen Dogmas und des Gottesgnadentums; immerhin konnten seine Protagonisten in dialektische und rhetorische Auseinandersetzungen verwickelt werden. In der Betulia liberata Metastasios - eleganter Vertreter der arkadisch-rationalistischen Strömung - wird dann sogar ein bestechender Gottesbeweis unter scharfsinniger, das heißt, stark rationaler Argumentation geführt. Die poetische Entfaltung der Oratoriendichtung unterliegt indessen selbstverständlich der allgemein literarischen Entwicklung. Denkwürdig erscheint freilich, dass während Spagna noch vom perfetto melodramma spirituale sprach, bei Zeno die azione sacra in die Nähe der hehren französischen Tragödie rückt, nur um dann in letzter Instanz unter Metastasios Händen endgültig ,melodrammatisiert' zu werden.

Der musikalische Werdegang der geistlichen Gattung erfolgt in absoluter Konformität mit dem ihrer weltlichen Schwester, der Oper. In kompositionstechnischer Hinsicht handelt es sich um den historischen Übergang vom Generalbass zur oberstimmenorientierten Arbeit. Die einzelnen Phasen, vom ersten Lockern der Generalbassstruktur, über die Aufgabe derselben, bis zu den ersten Umrissen eines blockhaften, melodisch horizontal ausgerichteten, metrisch regulierten Gefüges, dann der endgültigen Konsolidierung und der abschließenden Stagnation desselben, im Zeichen der Routine: alle sind in der Oratorienkomposition nachzuvollziehen. Als einzigen Unterschied könnte man die anspruchsvollere, häufig kontrapunktische Faktur der Oratorienchöre gegenüber jenen der Oper herausstellen, eine Charakteristik, die immerhin die Pflege der orchesterbegleiteten polyphonen Chöre in der italienischen Musik begünstigte. 
Die jeweilige Entwicklung der einzelnen Komponenten des italienischen Oratoriums ging folglich auf aparten Ebenen vonstatten, wobei man im Fall der Spiritualität nur begrenzt von einer richtigen Entwicklung sprechen kann. Dichtung und Komposition erreichten ihre relative Reife zeitlich differenziert; allerdings stellt sich die Frage, ob rein generalbassmäßige Musik nicht schon auch hinreichend ein anspruchsvolles Libretto geistlichen Inhalts zu tragen fähig war. Der ab 1720 aufblühende, neue italienische Stil war auf jeden Fall eher in der Lage, abgestufte Gefühle und Charaktere - von primärer Bedeutung in jeder dramatischen Form - angemessen zurückzugeben. Seine Überschneidung mit den Libretti Zenos und Metastasios hielt über einen bestimmten Zeitraum hindurch an und implizierte einen klassischen Zustand. Dass dieser allerdings schwebend und dynamisch war, zeigt seine über mehrere Jahrzehnte währende Fortdauer. Ein Beleg für diese These findet sich in der ständig neuen Beleuchtung gerade metastasianischer Oratoriendichtungen, durch zeitlich beträchtlich weit auseinander liegende Vertonungen. So wirkt La Passione di Gesù Cristo in der großartigen, ersten Version Caldaras von 1730 außerordentlich vergeistigt, wie es eben einem im Rahmen der Tradition des sepolcro aufgeführten Werk gebührte; Jomellis Komposition desselben Textes von 1749 ist weitaus sensueller, man sollte hinzufügen, sicherlich ganz im Sinne des Dichters; Salieri gestaltete seine Interpretation des Passionsoratoriums 1776 mit bis dahin nie realisierter Dramatik, und der bei der Aufführung anwesende, greise Metastasio fand sogar lobende Worte für seine Fassung; Paisiello, der den Text noch 1782 in Sankt Peterburg vertonte, beeindruckt durch eine kompositorische Dichte, die sich sehr jener der Wiener Klassiker annähert, zudem durch verschiedene formale Kühnheiten, die schon vieles vom künftigen durchkomponierten Prinzip vorwegnehmen. Die vier erwähnten Meister repräsentieren vier Phasen der kontinuierlichen Entwicklung der Kompositionstechnik im 18. Jahrhundert: die Klassizität ihrer Vertonungen im oben dargestellten Sinne steht außer Frage.

Johann Herczog (johann.herczog@tin.it), Conservatorio Santa Cecilia di Roma, Universität Szeged.

\section{ABSTRACT \\ SPIRITUALITY, POETRY AND COMPOSITION. THE VARYING LEVELS IN THE EVOLUTION OF ITALIAN ORATORIO}

\footnotetext{
Although the Italian Oratorio has its origins in the spiritual exercises of Filippo Neri, in the 17th century, as a musical-dramatic genre in formal-technical terms, it approaches the form of Opera. So from his secular counterpart it differs mainly by its close ties to the contents of Catholic faith. Its constituent factors, which we have to recognize in the spiritual topic, the poetry and the composition, are all singularly subjected to different, chronologically shifted developments of their gradients. The spirituality, strictly monitored by the Catholic Church, inevitably remains rather static, but cannot totally escape several intellectual-historical dynamics. Local traditions there often play a crucial role, as it shows a comparison between Rome, Naples, Venice and Vienna, all important centers of the Italian Oratorio. The literary development can be exemplified by the work of three representati-
} 
ve poets: Arcangelo Spagna, author also of a famous treatise about the Oratorio, Apostolo Zeno and Metastasio. As well as all writing Operas the two last, Court Poets in Vienna, had to comply with their librettos also the elitist imperial claim of the Habsburgs. Nevertheless, in their poems one can find an interesting development, which starts from fideism, for opening later, carefully, to various tendencies of rationalism. Observing the compositional technique the evolution of the Italian Oratorio is very similar to that of the Opera, characterized by the transition from the basso continuo to the new top part oriented musical structure, controlled by a symmetrical, cadenza-metrical implement. Generations of Italian composers contributed to the relative process. However, when all the three constituent factors of the Italian Oratorio - spirituality, poetry and composition - stabilize at an equally high level, we can speak of a classical state.

\section{Key words}

oratorio, italian oratorio, oratorio libretto, oratorio and poetry, oratorio and musical structure, oratorio in Rome, oratorio in Naples, oratorio in Venice, venetian conservatories, oratorio in Vienna, sepolcro in Vienna, Arcangelo Spagna, Discorso dogmatico, Apostolo Zeno, Poesie Sacre Drammatiche, Pietro Metastasio

\section{Bibliography}

ALALEONA, Domenico. Storia dell'Oratorio Musicale in Italia. Torino: Bocca, 1908.

BASSO, Alberto. L'invenzione della gioia. Musica e massoneria nell'età dei Lumi. Milano: Garzanti, 1994.

BELLOCCI, Ugo, ed. Tutte le encicliche e i principali documenti pontifici emanati dal 1740. 250 anni di storia visti dalla Santa Sede. Roma: Libreria Editrice Vaticana, vol. I, Benedetto XIV (1740-1758), 1993.

BESUTTI, Paola, ed. L'oratorio musicale italiano e i suoi contesti (secc. XVII-XVIII). Atti del Convegno Internazionale Perugia, Sagra Musicale Umbra, 18-20 settembre 1997. Firenze: Leo S. Olschki, 2002.

BRUNELLI, Bruno, ed. Tutte le opere di Pietro Metastasio. Milano: Mondadori, voll. I-IV, 1953-1954.

COTTICELLI, Francesco - MAIONE, Paologiovanni, ed. Storia della musica e dello spettacolo a Napoli. Il Settecento. vol. I, Napoli: CMA Pietà dei Turchini, 2009.

CROCE, Benedetto. I teatri di Napoli dal Rinascimento al secolo Decimottavo. Bari: Laterza, 1947.

FEHR, Max. Apostolo Zeno (1668-1750) und seine Reform des Operntextes. Zürich: Tschopp, 1912.

FLORIMO, Francesco. La Scuola Musicale di Napoli e i suoi conservatorii, con uno sguardo sulla storia della musica in Italia. Napoli: Morano, voll. I-IV, 1880-1882.

GASBARRI, Carlo. L'oratorio romano dal Cinquecento al Novecento. Roma: s. e., 1963.

GIUNTELLA, Vittorio E. Roma nel Settecento. Bologna: Cappelli, 1971.

GOETHE, Johann Wolfgang von. Italienische Reise. In Goethes Werke, vol. 10, Berlin - Weimar: Aufbau Verlag, 1981.

GRUBER, Gernot. Das Wiener Sepolcro und Johann Joseph Fux. Graz: Johann Joseph Fux Gesellschaft, 1972.

HELL, Helmut. Die neapolitanische Opernsinfonie in der ersten Hälfte des 18. Jahrhunderts. Tutzing: Hans Schneider, 1971.

HERCZOG, Johann. Il perfetto melodramma spirituale. L'oratorio italiano nel suo periodo classico. Roma: Istituto di Bibliografia Musicale, 2013.

KIRKENDALE, Ursula. Antonio Caldara. Life and Venetian-Roman Oratorios. Firenze: Leo S. Olschki, 2007.

METASTASIO, Pietro. Poesie del Signor Abate Pietro Metastasio. Parigi: La Vedova Quillau, voll. I-IX, 1755. 
OSTHOFF, Wolfgang - WIESEND, Reinhard, ed. Colloquium Klassizität, Klassizismus, Klassik in der Musik um 1920-1950. Tutzing: Hans Schneider, 1988.

PASQUETTI, Guido. L'oratorio musicale in Italia. Firenze: Successori Le Monnier, 1906.

RIEDEL, Friedrich W. Kirchenmusik am Hofe Karls VI. (1711-1740). Untersuchungen zum Verhältnis von Zeremoniell und musikalischem Stil im Barockzeitalter. München-Salzburg: Emil Katzbichler, 1977.

SALVETTI, Guido. Musica religiosa e conservatorii napoletani: a proposito del San Guglielmo d'Aquitania di Pergolesi. Quaderni della Rivista Italiana di Musicologia, 1983, no. 9.

SCHERING, Arnold. Geschichte des Oratoriums. Leipzig: Breitkopf \& Härtel, 1911.

SMITHER, Howard. E. A History of the Oratorio. Chapel Hill-Oxford: University of North Caroline Press, voll. I-III, 1978-87.

SPAGNA, Arcangelo. Oratorii overo melodrammi sacri con un discorso dogmatico intorno l'istessa materia [...] Libro primo, Roma: Gio. Francesco Buagni, 1706.

VALENTE, Mario, ed. Legge poesia e mito. Giannone, Metastasio e Vico fra "tradizione" e "trasgressione" nella Napoli degli anni Venti del Settecento. Atti del Convegno Internazionale di Studi, Palazzo Serra di Cassano, Napoli, 3-5 marzo 1998. Roma: Aracne, 2001.

ZENO, Apostolo. Poesie Sacre Drammatiche. Venezia: Cristoforo Zane, 1735.

ZORZI, Alvise. La Repubblica del Leone. Storia di Venezia. Milano: Rusconi, 1979. 